\title{
Trophic structure of the pelagic food web in the East China Sea
}

Mei-Ling Bai ${ }^{12^{*}}$, Fan-Sian Lin ${ }^{1}$, Yu-Ching Lee ${ }^{1}$, Gwo-Ching Gong ${ }^{3}$ and Chih-hao Hsieh ${ }^{1,2,4}$

\begin{abstract}
Background: Trophic structure and trophic transfer efficiency are among the most fundamental characteristics of an ecosystem. They characterize the transfer of nutrient and energy and are crucial in estimating the yield of harvestable biomass. In this study, we investigated the regulation of trophic structure (phytoplankton, zooplankton, and larval fish abundance) and biomass ratio of zooplankton to phytoplankton (as an indicator of transfer efficiency) in the East China Sea, one of the largest marginal seas in the world and an important fishing ground.

Results: The results showed that when sea surface temperature was below $25^{\circ} \mathrm{C}$, temperature co-acted with resource availability (zooplankton for larval fish and phytoplankton for zooplankton) in determining the trophic structure. When sea surface temperature was above $25^{\circ} \mathrm{C}$, resource availability dominated the regulation of trophic structure. Biomass ratio of zooplankton to phytoplankton decreased with increasing phosphate concentration.
\end{abstract}

Conclusions: Our study suggested that the trophic structure of the East China Sea might be controlled by bottom-up processes, and this control is mediated by temperature.

Keywords: Bottom-up control; Top-down control; Transfer efficiency; Phytoplankton; Zooplankton; Fish; Temperature; Nutrient status; East China Sea

\section{Background}

The trophic structure organizes the biological components of an ecosystem and channels the flow of nutrient and energy; thus, its regulation is a central issue in ecological research (Ware and Thomson 2005; Casini et al. 2008; Llope et al. 2012). In some marine ecosystems, the biomass of each trophic level is largely determined by available resources, suggesting a bottom-up control (e.g., Iverson 1990; Ware and Thomson 2005; Chassot et al. 2007), whereas in other marine ecosystems, the predatorprey interaction at higher trophic levels cascades down to the lower ones, demonstrating a top-down process (e.g., Frank et al. 2005; Daskalov et al. 2007; Casini et al. 2008). Actually, both processes could act simultaneously in an ecosystem, and the balance of bottom-up versus topdown control might depend on the ecosystem's state and integrity (Hunter and Price 1992; Gripenberg and Roslin 2007).

\footnotetext{
* Correspondence: meilingbai@ntu.edu.tw

${ }^{1}$ Institute of Oceanography, National Taiwan University, Taipei 10617, Taiwan ${ }^{2}$ Ocean Data Bank, Ministry of Science and Technology, Taipei 10617, Taiwan Full list of author information is available at the end of the article
}

In addition to the direction of trophic interactions, the strength of these interactions, characterized by trophic transfer efficiency, is crucial for understanding many ecological processes (Pauly et al. 1998). Trophic transfer efficiency describes the proportion of prey production that is converted to predator production. It may influence trophic structure and food chain length (Hairston and Hairston 1993; Post 2002) and is necessary for estimating fishery production and the amount of carbon transfer (Pauly et al. 1998; Richardson and Jackson 2007). Therefore, great research efforts have been devoted to understand the regulation of trophic transfer efficiency, and the factors proposed include environmental conditions such as temperature, light or nutrients (Dickman et al. 2008; Davis et al. 2010; Hoekman 2010), the indirect effect from a third trophic level (bottom-up or topdown cascade) (Hairston and Hairston 1993; Dickman et al. 2008), and the composition, diversity and structure of the trophic levels in issue (Mallin and Paerl 1994; Ye et al. 2013).

Here, we investigated the trophic structure in the East China Sea (ECS), one of the largest marginal seas in the world. The ECS consists of a broad continental shelf

\section{Springer}


bordered by China Mainland, Taiwan Island, Japanese Archipelago, and Korean Peninsula and is characterized by a complex hydrographic system with highly seasonal dynamics (Ichikawa and Beardsley 2002; Takahashi and Morimoto 2013). Parallel to the eastern edge of the ECS, the Kuroshio Current flows northwards year round; along the China coast, the southward China Coastal Current dominates when the northeastern monsoon prevails, and the northward Taiwan Strait Warm Current enters from the south when the southwestern monsoon governs. Freshwater discharge from Changjiang at the northwest of the ECS and the Kuroshio upwelling at the southeast of the ECS are the main nutrient sources for the region (Liu et al. 1992; Gong et al. 2003). The ECS ever supported a productive fishery and rich biodiversity but has suffered heavy overfishing, eutrophication, and other disturbances in the past decades (Chen et al. 1997; Li et al. 2009).

Extensive studies have investigated the spatiotemporal variation in the abundance or composition of larval fish (Okazaki and Nakata 2007; Hsieh et al. 2011; Lefébure et al. 2013), zooplankton (e.g., Liao et al. 2006; Lan et al. 2008; Tseng et al. 2008), and phytoplankton (e.g., Gong et al. 2006; Liu et al. 2010; Gong et al. 2011) in the ECS. Many of these previous studies used the abundance of neighboring trophic levels to explain the variation of the focal study group, but the multi-level trophic interactions and the factors regulating them remained to be investigated. Furthermore, many studies focused on a specific season or a confined area in the ECS, and information about the overall pattern of this highly variable ecosystem was scarce. In this study, we analyzed the trophic interactions between larval fish, zooplankton, and phytoplankton using a dataset covering the entire ECS and comprised of data from different seasons. The main objective is to answer (1) whether the trophic structure of the ECS is controlled by a top-down or bottom-up process and how the processes are mediated by temperature, and (2) which factors may influence the trophic transfer efficiency from phytoplankton to zooplankton in the ECS.

\section{Methods}

Sample collection and data treatment

Biological samples and corresponding environmental data were collected in seven cruises between 2007 and 2010 over the ECS (Figure 1, Additional file 1: Table S1). Due to constraints of weather and ship time, not all stations were sampled during each cruise. In total, 120 sets of samples were used in the analyses. For collecting larval fishes and zooplankton, an ORI net (Omori 1965) with a mesh size of $330 \mu \mathrm{m}$ and a mouth diameter of $160 \mathrm{~cm}$ was towed obliquely from near the bottom to the sea surface. The volume of filtered water per tow was obtained from readings of a flowmeter attached to the net. At each sampling station, water temperature

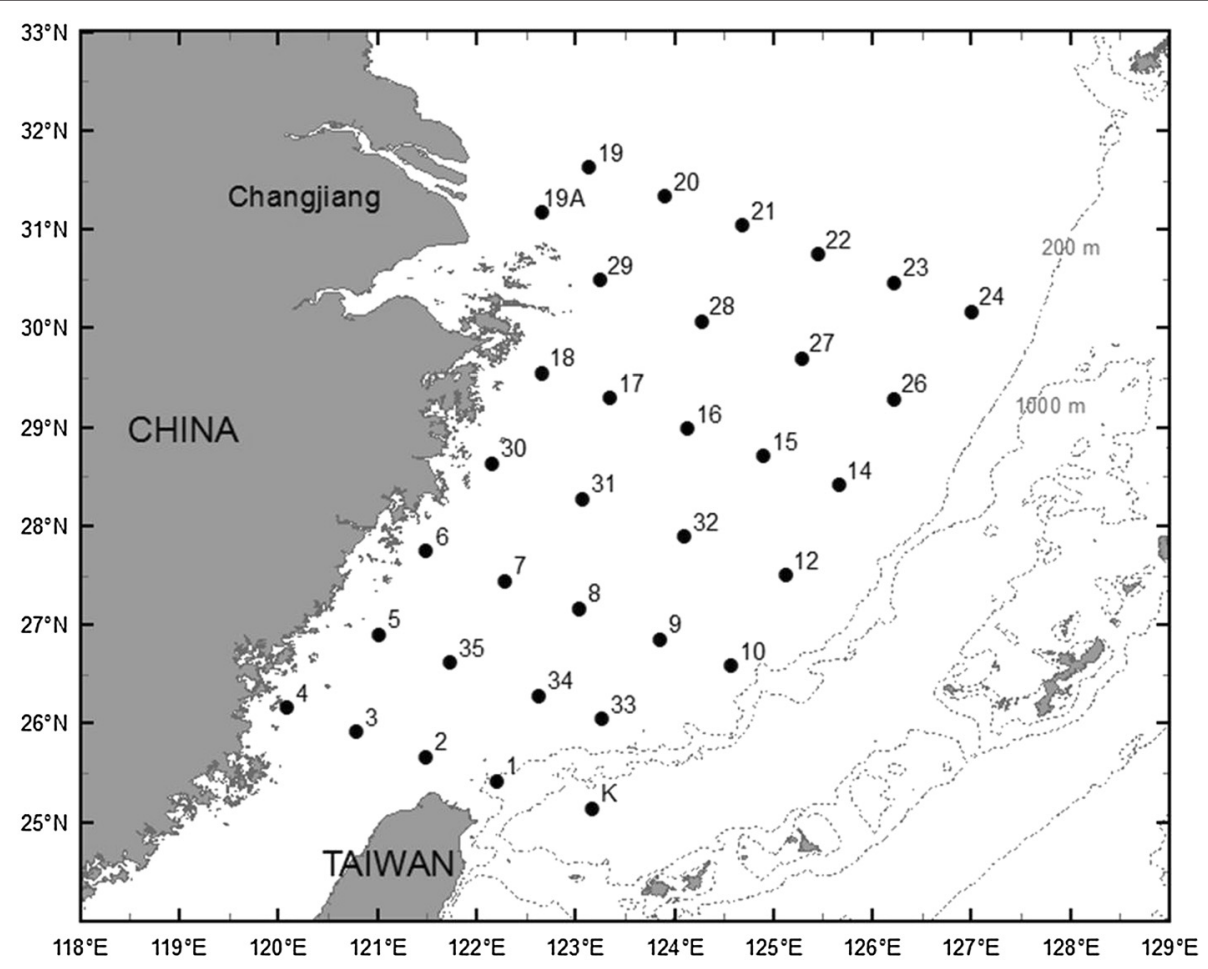

Figure 1 Location of sampling stations in the East China Sea. 
and salinity along the vertical profile were recorded with a CTD profiler (SBE 9/11 plus, SeaBird Inc., Bellevue, WA, USA). Seawater samples were taken using Go-Flo bottles at four to six depths spanning the water column. From these samples, concentrations of chlorophyll-a, nitrate $\left(\mathrm{NO}_{3}\right)$, nitrite $\left(\mathrm{NO}_{2}\right)$, ammonium $\left(\mathrm{NH}_{4}\right)$, phosphate $\left(\mathrm{PO}_{4}\right)$, and silicate $\left(\mathrm{SiO}_{3}\right)$ were analyzed according to the standard methods (Gong et al. 2003).

Larval fishes were counted and standardized to per cubic meter. The majority of larval fishes sampled in plankton nets are in very early stages of their development; therefore, their density can be used as a rough proxy for the abundance of spawning adults (Hsieh et al. 2009). We did not convert larval fish density to carbon biomass, as we had no adequate information about the length distribution and the weight-length relationship of larval fish, which are necessary for the conversion. The zooplankton settled volume was determined using the displacement method (Ballón et al. 2011). To exclude carnivorous zooplankton from the analyses, the samples were digitized with the ZooScan integrated system, and the scanned images were manually classified to calculate the volume percentage of chaetognaths and jellyfishes (Ye et al. 2011; Chang et al. 2012; García-Comas et al. 2013). The displacement volume of each sample was then modified by multiplying a factor of $(1-$ percentage of carnivorous zooplankton) and then converted to carbon biomass based on the regression formula from the literature (Wiebe 1988; Sánchez and Olaso 2004). Chlorophyll-a concentration was averaged over the towing depth and converted to carbon biomass using a carbon: chlorophyll-a ratio of 30 (Geider 1987). The abundance of larval fish and the biomasses of zooplankton and phytoplankton were log-transformed prior to analyses. Concentrations of dissolved inorganic nitrogen (DIN, sum of $\mathrm{NO}_{3}, \mathrm{NO}_{2}$, and $\left.\mathrm{NH}_{4}\right), \mathrm{PO}_{4}$ and $\mathrm{SiO}_{3}$ were averaged over the towing depth to indicate the nutrient status of each station. Sea surface temperature (SST) and surface salinity (SSS) were adopted to indicate the physical features of the water.

The log-transformed ratio of zooplankton biomass to phytoplankton biomass (Z:P ratio) was calculated as an indicator of the trophic transfer efficiency from phytoplankton to zooplankton. The actual trophic transfer efficiency, defined as the production ratio of predator versus prey, is very difficult to derive in natural marine ecosystems. Therefore, the biomass ratio of adjacent trophic levels has been used to infer the trophic transfer efficiency (Gaedke and Straile 1994), despite that biomass ratios may differ from production ratios and biomass development of different trophic levels may not be perfectly synchronized. A recent work, using the shipboard incubation method to measure the production of zooplankton and phytoplankton in the ECS, has proved that there is indeed a very strong correlation between biomass ratio and production ratio for the two tropic levels ( $\mathrm{Su}$, in preparation).

\section{Data analysis}

We applied mixed-effects models to investigate which factors may affect the abundance of each trophic level and the Z:P ratio. For the larval fish density, we used the biomass of zooplankton (food for fish), SST and SSS as fixed-effect variables. For the biomass of zooplankton, we used both the larval fish density (proxy of predation on zooplankton) and the biomass of phytoplankton (food for zooplankton) as well as SST and SSS as fixedeffect variables. For the biomass of phytoplankton, we used the biomass of zooplankton (proxy of predation on phytoplankton), nutrient status (DIN, $\mathrm{PO}_{4}$, and $\mathrm{SiO}_{3}$, which represent resources for phytoplankton), as well as SST and SSS as fixed-effect variables. For the Z:P ratio, we used larval fish density, SST, SSS, and nutrient status as fixed-effect variables. We considered sampling cruise as a random effect on both intercept and slope in all analyses to account for variation among cruises, such as seasonal effects.

As ecological relationships might show an abrupt change which could indicate a change in underlying mechanisms, we used piecewise regression analysis to detect potential discontinuities in univariate models prior to multivariate analyses (Toms and Lesperance 2003; Casini et al. 2009). Both the mixed-effects piecewise regression and generalized linear mixed-effects model (GLMM) (Bolker et al. 2009) were applied to model the relationship between each response variable and each predictor. Fits of the two models were then compared based on Akaike's information criterion (AIC) (Akaike 1974). A reduction of 10 units or more in AIC values is generally considered as a significant improvement of the model fit (Bolker et al. 2009). Therefore, we treated a relationship as segmented when the piecewise model had an AIC value of at least 10 units lower than the linear model $(\triangle \mathrm{AIC} \geq 10)$, and conducted the following analyses for the specific response variable in groups delineated by the point of discontinuity estimated by the piecewise model with best fit.

We then used multivariate GLMMs with normal distribution and identity link function to identify the variable combinations that could best model the biomass of each trophic level and trophic efficiency. For each response variable, all corresponding fixed-effect variables were included in the initial model, and backward stepwise selection was applied. The best models were determined based on AIC. The piecewise regression analysis and GLMMs were performed with NLMIXED and GLIMMIX procedures, respectively, in SAS 9.3 (SAS Institute Inc., Cary, NC, USA). 
We further examined how much variance of the abundance/biomass of each trophic level could be explained by the abundance/biomass of other trophic levels by calculating the marginal $R_{\text {GLMM }}^{2}$ (Nakagawa and Schielzeth 2013). Although the AIC value and other information criteria are useful for comparing and selecting models, they provide no information about the absolute model fit and are not comparable between different datasets (Burnham et al. 2011). A recent statistical development offers a method for calculating the variance explained by the fixed effect (marginal $R_{\text {GLMM }}^{2}$ ) and comparing crossdatasets model fit for GLMMs (Nakagawa and Schielzeth 2013). We constructed GLMMs for the abundance/ biomass of each trophic level using only the abundance of one of the other trophic levels as the fixed effect, and then calculated the marginal $R_{\text {GLMM }}^{2}$ as an indicator of the strength of trophic interactions. The $R_{\mathrm{GLMM}}^{2}$ was calculated using the MuMIn package in $\mathrm{R}$ ( $\mathrm{R}$ Core Team).

\section{Results}

In univariate analyses, the variation of larval fish density could be best described by the piecewise model of SST (Table 1). Larval fish density increased with increasing SST when SST was lower than $25.3^{\circ} \mathrm{C}$, but decreased with increasing SST when SST was higher (Figure 2). For phytoplankton biomass, abrupt changes occurred in its relationships with SST (at SST $=24.8^{\circ} \mathrm{C}$ ), SSS (at SSS $=32.0$ psu), and DIN (at DIN $=10.4 \mu \mathrm{M}$ ), and the piecewise model based on SST had the best fit among all models.
Therefore, we built multivariate GLMMs for larval fish density and phytoplankton biomass in the temperature ranges above and below $25^{\circ} \mathrm{C}$, separately. However, for the zooplankton biomass and the $\mathrm{Z}: \mathrm{P}$ ratio, no piecewise model performed significantly better than the corresponding linear model according to the criterion of $\triangle \mathrm{AIC} \geq 10$. Thus, for the zooplankton biomass and the Z:P ratio, we used the complete dataset. Nevertheless, we additionally modeled zooplankton biomass in the two temperature ranges for comparison purposes.

The results of multivariate GLMMs showed that bottom-up forces played an important role in shaping the trophic structure of the ECS (Table 2). In both temperature ranges, the biomass of phytoplankton was determined only by physical and nutritional variables, the zooplankton biomass increased with increasing phytoplankton biomass, and the larval fish density increased with increasing zooplankton biomass. The larval fish density was positively correlated with both zooplankton biomass and SST when SST was below $25^{\circ} \mathrm{C}$. When SST was above $25^{\circ} \mathrm{C}$, only zooplankton biomass influenced larval fish density. Zooplankton biomass could be best explained by phytoplankton biomass when using the complete dataset, although, when SST was below $25^{\circ} \mathrm{C}$, the model including the effect of SST in addition to phytoplankton biomass offered a better fit to zooplankton biomass than the model with phytoplankton biomass alone. For the Z:P ratio, only the negative effect of $\mathrm{PO}_{4}$ concentration was included in the final model.

Table 1 Comparison of linear models and piecewise models

\begin{tabular}{|c|c|c|c|c|}
\hline Response & Predictor & AIC linear model & AIC piecewise model & Cut point \\
\hline \multirow[t]{3}{*}{ Larval fish } & $\mathrm{SST}^{\mathrm{a}}$ & 452.1 & 440.5 & 25.3 \\
\hline & SSS & 460.6 & 462.1 & 32.2 \\
\hline & Zooplankton biomass & 446.6 & 447.0 & -1.9 \\
\hline \multirow[t]{3}{*}{ Zooplankton } & SST & 358.4 & 360.2 & 25.2 \\
\hline & SSS & 363.9 & 362.9 & 32.8 \\
\hline & Phytoplankton biomass & 354.2 & 358.0 & 8.9 \\
\hline \multirow[t]{5}{*}{ Phytoplankton } & $\mathrm{SST}^{\mathrm{a}}$ & 216.0 & 192.6 & 24.8 \\
\hline & $\mathrm{SSS}^{\mathrm{a}}$ & 216.6 & 204.7 & 32.0 \\
\hline & $\mathrm{DIN}^{\mathrm{a}}$ & 211.4 & 198.9 & 10.4 \\
\hline & $\mathrm{PO}_{4}$ & 219.4 & 223.4 & 0.2 \\
\hline & $\mathrm{SiO}_{3}$ & 219.6 & 213.1 & 16.3 \\
\hline \multirow[t]{6}{*}{ Zooplankton/phytoplankton ratio } & SST & 363.0 & 364.8 & 24.5 \\
\hline & SSS & 362.4 & 365.4 & 28.3 \\
\hline & DIN & 353.2 & 355.5 & 9.0 \\
\hline & $\mathrm{PO}_{4}$ & 342.9 & 348.2 & 0.5 \\
\hline & $\mathrm{SiO}_{3}$ & 353.8 & 356.8 & 4.7 \\
\hline & Larval fish density & 356.2 & 360.2 & -1.3 \\
\hline
\end{tabular}

The relationships between the abundance/biomass of each trophic level and each predictor variable were analyzed using generalized linear mixed-effects models and mixed-effects piecewise regression models, and the AIC values of the two approaches were compared.

${ }^{a}$ The piecewise model had a much better fit compared to the linear model ( $\triangle \mathrm{AIC} \geq 10$ ), indicating a change of relationship at the cut point. 


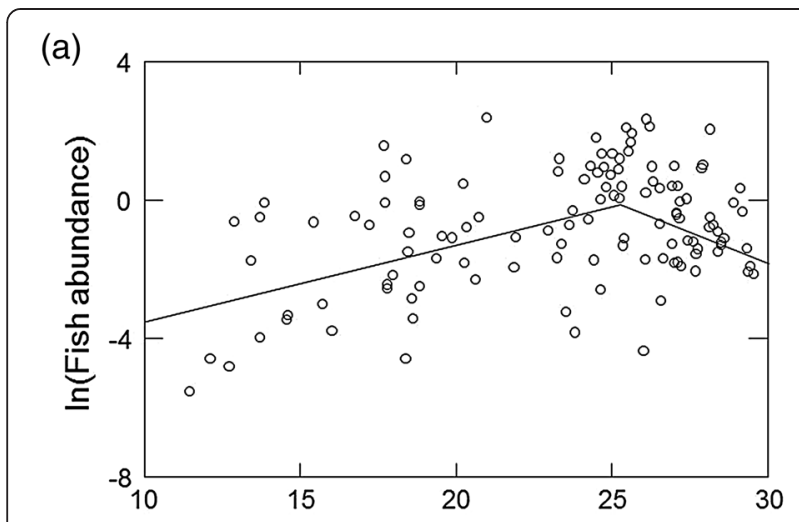

(b)

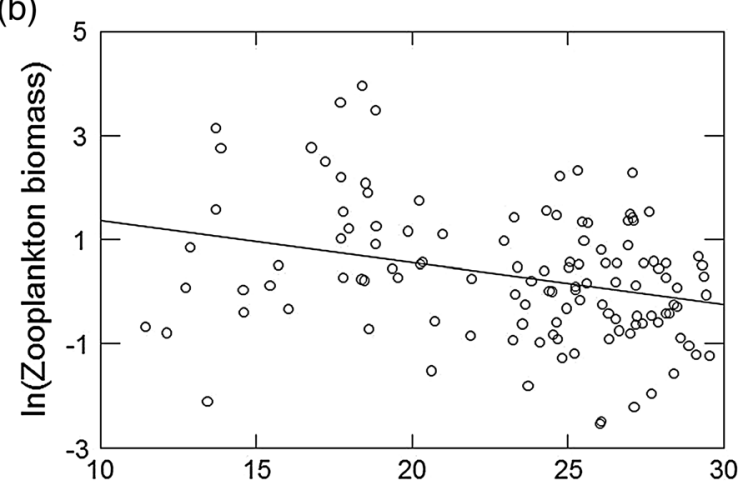

(c)

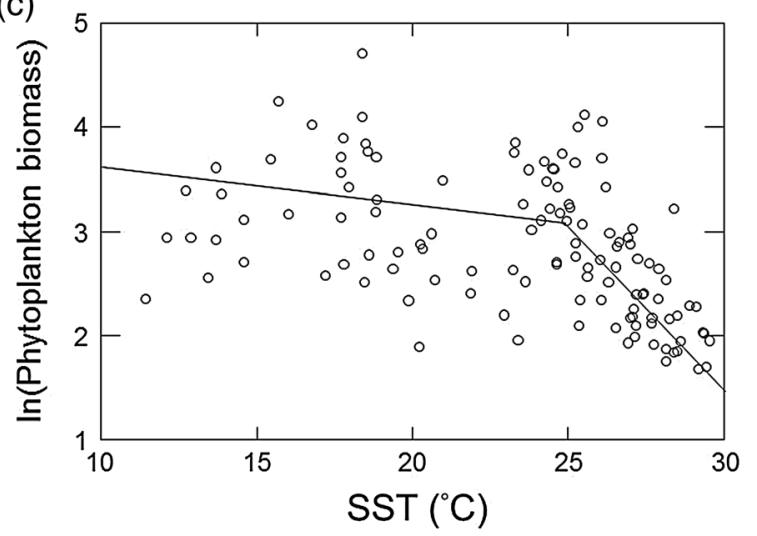

Figure 2 Relationships between the abundance/biomass of each trophic level and SST. (a) Larval fish abundance and SST, (b) zooplankton biomass and SST, and (c) phytoplankton biomass and SST. The trend lines were based on piecewise regression with random effects in (a) and (c), and on generalized linear mixed models in (b).

When SST was below $25^{\circ} \mathrm{C}$, about $9 \%$ of the variation in larval fish density could be explained by zooplankton biomass, and about $5 \%$ of the variation in zooplankton biomass could be explained by phytoplankton biomass (Figure 3). When SST was above $25^{\circ} \mathrm{C}$, the explained variation of larval fish density by zooplankton biomass and zooplankton biomass by phytoplankton biomass raised to $23 \%$ and $14 \%$, respectively. Less than $1 \%$ of the variation in larval fish density could be explained by phytoplankton biomass when SST was below $25^{\circ} \mathrm{C}$, while $21 \%$ could be explained by phytoplankton biomass when SST was higher.

\section{Discussion}

Our study suggested that the bottom-up control regulates the trophic structure in the East China Sea, and this control is mediated by temperature (Table 2, Figure 3). The results of multiple GLMMs showed that temperature coacted with resource availability in determining the trophic structure when SST was below $25^{\circ} \mathrm{C}$ (Table 2). Correspondingly, phytoplankton biomass alone was a poor predictor for zooplankton biomass, and likewise, zooplankton biomass alone was a poor predictor for larval fish density (Figure 3). By contrast, while SST was above $25^{\circ} \mathrm{C}$, the bottom-up process dominated the regulation of trophic structure; thus, the trophic levels were well coupled and the fish production could be better predicted by primary production.

It is worthy to clarify the effects of temperature on trophic structure in the ECS. We found that the relationship between phytoplankton biomass and temperature showed an abrupt change at SST of about $25^{\circ} \mathrm{C}$ (Table 1 , Figure 2). Such a change may be related to the spatiotemporal variation of the temperature and nutrient conditions in the system. Specifically, the temperature of the coastal area affected by the Changjiang discharge (the main source of nutrient input into the ECS) is relatively low and changes seasonally (SST from $11^{\circ} \mathrm{C}$ to $26^{\circ} \mathrm{C}$; Gong et al. 2003). On the contrary, the oligotrophic Kuroshio Current bordering the ECS is warm and relatively stable in temperature (SST from $20^{\circ} \mathrm{C}$ to $30^{\circ} \mathrm{C}$ ). That is, the nutrient level is negatively correlated with water temperature in the ECS, and the decline is particularly sharp when the shelf water encounters the Kuroshio Current, on average at SST around $25^{\circ} \mathrm{C}$. It is well known that SST is a reasonable proxy for nutrient status in the ECS (Gong et al. 2003). Thus, our finding of the relationship between phytoplankton biomass and temperature (Figure 2) basically signals the bottom-up effects of nutrient on phytoplankton, which is mediated by the hydrography of ECS. Indeed, the phytoplankton biomass also showed a significant relationship with nutrients (Table 1 ).

The change of the relationship between fish abundance and SST at about $25^{\circ} \mathrm{C}$ (Table 1, Figure 2) may be related to the physiology of fish, the change in fish assemblage, and food availability. When SST was below $25^{\circ} \mathrm{C}$, the larval fish abundance was positively correlated with SST. This observed relationship could be underlain by the fact that fish assemblage changes along the temperature gradient (Hsieh et al. 2011; Lefébure et al. 2013) and different fish species may have different physiological responses. Note, however, that zooplankton biomass also play some roles when SST is below $25^{\circ} \mathrm{C}$ 
Table 2 Generalized linear mixed-effects models for the abundance/biomass of each trophic level and the Z:P ratio

\begin{tabular}{|c|c|c|c|c|c|c|}
\hline Model & AIC of final model & Variables in final model & Estimate & SE & $\mathbf{t}$ & $\mathbf{P}$ \\
\hline Larval fish $\left(\mathrm{SST} \leq 25^{\circ} \mathrm{C}\right)$ & 231.4 & & & & & \\
\hline \multirow[t]{2}{*}{ Zooplankton, SST, SSS } & & Zooplankton biomass & 0.485 & 0.201 & 2.40 & $<0.05$ \\
\hline & & SST & 0.279 & 0.052 & 5.32 & $<0.01$ \\
\hline Larval fish (SST $>25^{\circ} \mathrm{C}$ ) & 198.1 & & & & & \\
\hline Zooplankton, SST, SSS & & Zooplankton biomass & 0.657 & 0.170 & 3.87 & $<0.05$ \\
\hline Zooplankton (full range) & 354.2 & & & & & \\
\hline Fish, phytoplankton SST, SSS & & Phytoplankton biomass & 0.565 & 0.143 & 3.94 & $<0.01$ \\
\hline Zooplankton (SST $\leq 25^{\circ} \mathrm{C}$ ) & 195.8 & & & & & \\
\hline \multirow[t]{2}{*}{$\sim$ Fish, phytoplankton SST, SSS } & & Phytoplankton biomass & 0.593 & 0.261 & 2.36 & 0.05 \\
\hline & & SST & -0.065 & 0.047 & -1.39 & 0.22 \\
\hline Zooplankton (SST > 25 ${ }^{\circ} \mathrm{C}$ ) & 157.6 & & & & & \\
\hline$\sim$ Fish, phytoplankton SST, SSS & & Phytoplankton biomass & 0.643 & 0.190 & 3.38 & $<0.05$ \\
\hline Phytoplankton (SST $\leq 25^{\circ} \mathrm{C}$ ) & 100.9 & & & & & \\
\hline \multirow[t]{3}{*}{ Zooplankton, SST, SSS, nutrients } & & SST & -0.057 & 0.023 & -2.52 & 0.05 \\
\hline & & SSS & -0.149 & 0.048 & -3.09 & $<0.05$ \\
\hline & & $\mathrm{PO}_{4}$ & 0.673 & 0.488 & 1.38 & 0.22 \\
\hline Phytoplankton (SST $>25^{\circ} \mathrm{C}$ ) & 71.5 & & & & & \\
\hline \multirow[t]{3}{*}{ Zooplankton, SST, SSS, nutrients } & & SST & -0.193 & 0.047 & -4.07 & $<0.05$ \\
\hline & & SSS & -0.096 & 0.026 & -3.76 & $<0.05$ \\
\hline & & $\mathrm{PO}_{4}$ & 0.585 & 0.480 & 1.22 & 0.30 \\
\hline Zooplankton/phytoplankton ratio (full range) & 342.9 & & & & & \\
\hline$\sim$ Fish, SST, SSS, nutrients & & $\mathrm{PO}_{4}$ & -1.729 & 0.439 & -3.87 & $<0.01$ \\
\hline
\end{tabular}

(Table 2, Figure 3a). When SST was above $25^{\circ} \mathrm{C}$, the larval fish abundance decreased with increasing temperature. The change of fish assemblage along the temperature gradient could not provide a satisfactory explanation for this unexpected finding, as SST was not a significant predictor in the multivariate GLMMs (Table 2). The observed relationship between fish abundance and SST in warm waters could be best explained by food availability. Specifically, in the ECS, the biomass of zooplankton decreases with increasing water temperature, as a result of decreasing phytoplankton biomass through the bottom-up control. At SST above $25^{\circ} \mathrm{C}$, the larval fish abundance is limited by zooplankton abundance and the increase of temperature exhibits no beneficial effects to the larval fish abundance. Our analyses are consistent with the results of Chen et al. (2014), which suggested that the abundance of larval fish in the ECS was mainly affected by SST in the cool season and by food availability in the warm season.

Our finding that the bottom-up control regulates the trophic structure in the East China Sea (Table 2, Figure 3) is consistent with the patterns found along the continental margin of western North America (Ware and Thomson 2005) and with the study using the cross-system comparative method (Iverson 1990). However, our finding is in contrast with some studies in the over-exploited ecosystems of northwest Atlantic (Frank et al. 2005), the Black Sea (Daskalov et al. 2007), and the Baltic Sea (Casini et al. 2008; Mollmann et al. 2008; Casini et al. 2009), where the top-down process and trophic cascade were found to control the trophic structure after the removal of top predators. Despite being heavily exploited (Chen et al. 1997; Liu and Zhan 1999), the top-down control did not dominate the ECS ecosystem in the trophic levels we examined. The current extent of exploitation and the more diverse community of the subtropical ECS compared to the other studied over-exploited systems could be part of the reason, as simpler food webs are more likely to be governed by top-down regulation (Bascompte et al. 2005; Frank et al. 2007). The regulating mechanism of the trophic structure may nevertheless change over time (Casini et al. 2009; Davis et al. 2010). Our results provide the scenario in the ECS between 2007 and 2010. It is worth further monitoring that, under the continuing natural and artificial changes into its environment and biological communities, whether the regulating mechanism in the ECS may alter.

We found that the Z:P ratio decreased with increasing $\mathrm{PO}_{4}$ concentration (Table 2). Similar results have been found in phosphate-limited environments and could indicate a cascade effect that regulates trophic transfer 

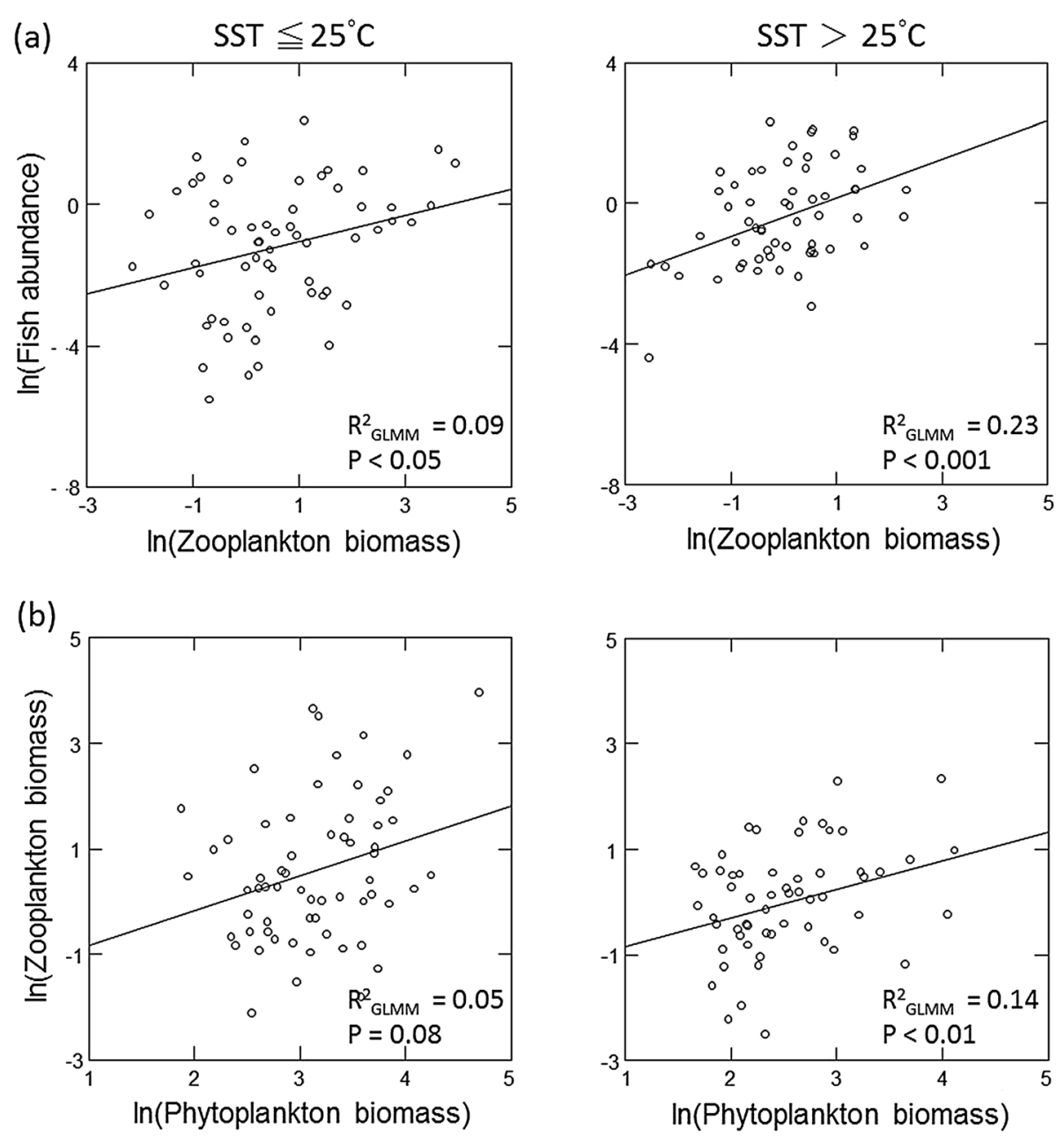

(c)
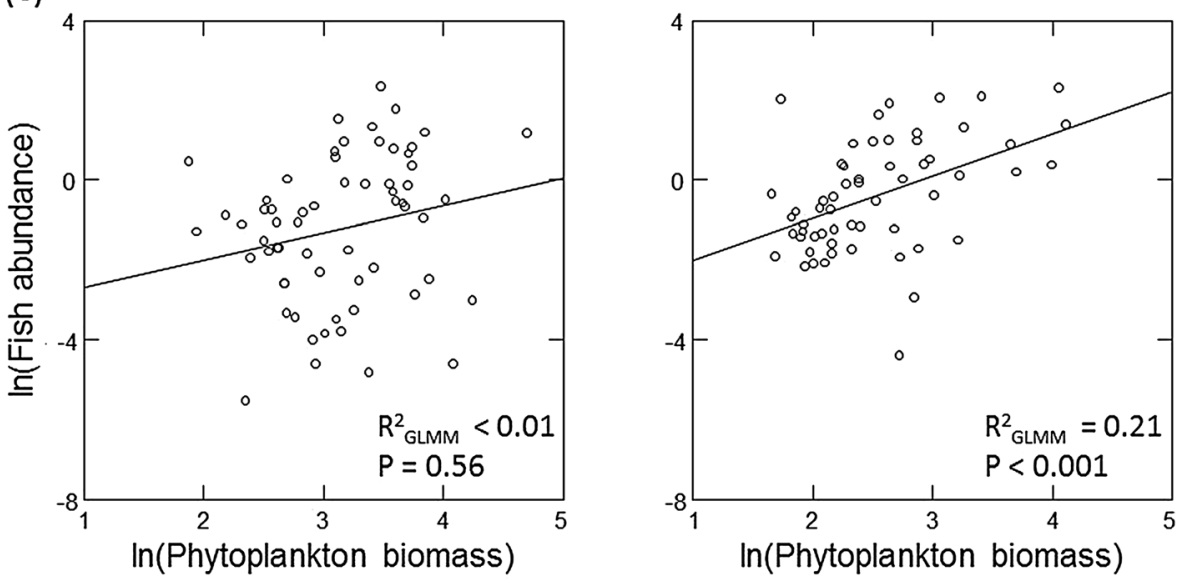

Figure 3 Relationships between the abundance/biomass of different trophic levels. (a) Larval fish abundance versus zooplankton biomass, (b) zooplankton biomass versus phytoplankton biomass, and (c) larval fish abundance versus phytoplankton biomass when SST $\leq 25^{\circ} \mathrm{C}$ and when SST $>25^{\circ} \mathrm{C}$. The trend lines were based on generalized linear mixed models.

efficiency (Jeppesen et al. 1997, 2003; Dickman et al. 2008). Increasing concentration of $\mathrm{PO}_{4}$ may boost the growth of fish via high food quality. This would result in a high predation rate of fish on zooplankton, which then further suppresses the grazing pressure of zooplankton on phytoplankton. Whether this is the actual mechanism 
operating in the ECS, though, remains to be further investigated.

We recognize that this study was based on a simplified tri-trophic food chain, whereas the real food web is much more complicated (Bascompte and Melian 2005). For example, the microbial loop may provide mesozooplankton with additional food sources (del Giorgio and Gasol 1995). The microzooplankton may have significant grazing impact on phytoplankton as well as contribute to the diet of mesozooplankton (Calbet 2008). However, we currently do not have the data to evaluate the roles of the microbial loop and microzooplankton. The current correlation analyses, nevertheless, reveal interesting information that may provide a first step for further investigation into the mechanisms.

\section{Conclusions}

In summary, our study suggested that the bottom-up control is the prevailing mechanism regulating the trophic structure of the East China Sea. We also demonstrated how temperature and nutrient status influence the abundance of each trophic level. Our study could offer a base in further understating how eutrophication and temperature change may influence the ecosystem of the East China Sea.

\section{Additional file}

Additional file 1: Table S1. Date and sampling stations of each cruise used in this study.

\section{Competing interests}

The authors declare that they have no competing interests.

\section{Authors' contributions}

$\mathrm{CHH}$ designed and conceptualized this study. GCC collected the nutrient and chlorophyll data. FSL and YCL quantified zooplankton and fish samples and performed the ZooScan analysis. MLB performed the statistical analysis. MLB and $\mathrm{CHH}$ drafted the manuscript. All authors read and approved the final manuscript.

\section{Acknowledgements}

This research is supported by the National Taiwan University and National Science Council, Taiwan. We thank the crews of the RN 'Ocean Researcher I and II' for their assistance in the sampling.

\section{Author details}

'Institute of Oceanography, National Taiwan University, Taipei 10617, Taiwan. ${ }^{2}$ Ocean Data Bank, Ministry of Science and Technology, Taipei 10617, Taiwan. ${ }^{3}$ Center of Excellence for the Oceans, National Taiwan Ocean University, Keelung 20224, Taiwan. ${ }^{4}$ Institute of Ecology and Evolutionary Biology, National Taiwan University, Taipei 10617, Taiwan.

Received: 16 December 2013 Accepted: 16 December 2014 Published online: 09 January 2015

\section{References}

Akaike H (1974) A new look at the statistical model identification. IEEE Trans Automat Contr 19(6):716-723, doi:10.1109/TAC.1974.1100705

Ballón M, Bertrand A, Lebourges-Dhaussy A, Gutiérrez M, Ayón P, Grados D, Gerlotto F (2011) Is there enough zooplankton to feed forage fish populations off Peru? An acoustic (positive) answer. Prog Oceanogr 91(4):360-381, doi:10.1016/j.pocean.2011.03.001

Bascompte J, Melian CJ $(2005)$ Simple trophic modules for complex food webs. Ecology 86:2868-2873, doi:10.1890/05-0101

Bascompte J, Melian CJ, Sala E (2005) Interaction strength combinations and the overfishing of a marine food web. Proc Natl Acad Sci Unit States Am 102(15):5443-5447, doi: 10.1073/pnas.0501562102

Bolker BM, Brooks ME, Clark CJ, Geange SW, Poulsen JR, Stevens MHH, White J-SS (2009) Generalized linear mixed models: a practical guide for ecology and evolution. Trends Ecol Evol 24(3):127-135, doi:10.1016/j.tree.2008.10.008

Burnham K, Anderson D, Huyvaert K (2011) AIC model selection and multimodel inference in behavioral ecology: some background, observations, and comparisons. Behav Ecol Sociobiol 65(2):415-415, doi:10.1007/s00265-0101084-z

Calbet A (2008) The trophic roles of microzooplankton in marine systems. ICES J Mar Sci 65(3):325-331, doi:10.1093/icesjms/fsn013

Casini M, Hjelm J, Molinero J-C, Lovgren J, Cardinale M, Bartolino V, Belgrano A, Kornilovs G (2009) Trophic cascades promote threshold-like shifts in pelagic marine ecosystems. Proc Natl Acad Sci Unit States Am 106(1):197-202, doi:10.1073/pnas.0806649105

Casini M, Lövgren J, Hjelm J, Cardinale M, Molinero J-C, Kornilovs G (2008) Multi-level trophic cascades in a heavily exploited open marine ecosystem. Proc Roy Soc Edinb B Biol 275(1644):1793-1801, doi:10.1098/rspb.2007.1752

Chang C-Y, Ho P-C, Sastri AR, Lee Y-C, Gong G-C, C-h H (2012) Methods of training set construction: towards improving performance for automated mesozooplankton image classification systems. Cont Shelf Res 36:19-28, doi:10.1016/j.csr.2012.01.005

Chassot E, Melin F, Le Pape O, Gascuel D (2007) Bottom-up control regulates fisheries production at the scale of eco-regions in European seas. Mar Ecol Prog Ser 343:45-55, doi: 10.3354/meps06919

Chen WY, Lee MA, Lan KW, Gong GC (2014) Distributions and assemblages of larval fish in the East China Sea during the northeasterly and southwesterly monsoon seasons of 2008. Biogeosciences 11(3):547-561, doi:10.5194/bg-11547-2014

Chen WZ, Zheng YZ, Chen YQ, Mathews CP (1997) An assessment of fishery yields from the East China Sea ecosystem. Mar Fish Rev 59(4):1-7

Daskalov GM, Grishin AN, Rodionov S, Mihneva V (2007) Trophic cascades triggered by overfishing reveal possible mechanisms of ecosystem regime shifts. Proc Natl Acad Sci Unit States Am 104(25):10518-10523, doi:10.1073/ pnas.0701100104

Davis JM, Rosemond AD, Eggert SL, Cross WF, Wallace JB (2010) Long-term nutrient enrichment decouples predator and prey production. Proc Natl Acad Sci Unit States Am 107(1):121-126, doi:10.1073/pnas.0908497107

del Giorgio PA, Gasol JM (1995) Biomass distribution in freshwater plankton communities. Am Nat 146(1):135-152

Dickman EM, Newell JM, González MJ, Vanni MJ (2008) Light, nutrients, and foodchain length constrain planktonic energy transfer efficiency across multiple trophic levels. Proc Natl Acad Sci Unit States Am 105(47):18408-18412, doi:10.1073/pnas.0805566105

Frank KT, Petrie B, Choi JS, Leggett WC (2005) Trophic cascades in a formerly cod-dominated ecosystem. Science 308:1621-1623, doi:10.1126/ science. 1113075

Frank KT, Petrie B, Shackell NL (2007) The ups and downs of trophic control in continental shelf ecosystems. Trends Ecol Evol 22(5):236-242, doi:10.1016/j. tree.2007.03.002

Gaedke U, Straile D (1994) Seasonal-changes of trophic transfer efficiencies in a plankton food-web derived from biomass size distributions and network analysis. Ecol Model 75:435-445, doi:10.1016/0304-3800(94)90038-8

García-Comas C, Chang C-Y, Ye L, Sastri AR, Lee Y-C, Gong G-C, Hsieh C-h (2013) Mesozooplankton size structure in response to environmental conditions in the East China Sea: how much does size spectra theory fit empirical data of a dynamic coastal area? Progr Oceanogr. doi:10.1016/.jpocean.2013.10.010

Geider RJ (1987) Light and temperature dependence of the carbon to chlorophyll a ratio in microalgae and cyanobacteria: implications for physiology and growth of phytoplankton. New Phytol 106(1):1-34, doi:10.2307/2434683

Gong G-C, Chang J, Chiang KP, Hsiung TM, Hung CC, Duan SW, Codispoti LA (2006) Reduction of primary production and changing of nutrient ratio in the East China Sea: effect of the Three Gorges Dam? Geophys Res Lett 33:L07610, doi:10.1029/2006GL025800

Gong G-C, Liu K-K, Chiang K-P, Hsiung T-M, Chang J, Chen C-C, Hung C-C, Chou W-C, Chung C-C, Chen H-Y, Shiah F-K, Tsai A-Y, C-h H, Shiao J-C, Tseng C-M, 
Hsu S-C, Lee H-J, Lee M-A, Lin II, Tsai F (2011) Yangtze River floods enhance coastal ocean phytoplankton biomass and potential fish production. Geophys Res Lett 38(13), L13603, doi:10.1029/201 gl047519

Gong G-C, Wen Y-H, Wang B-W, Liu G-J (2003) Seasonal variation of chlorophyll a concentration, primary production and environmental conditions in the subtropical East China Sea. Deep Sea Res Part II 50(6-7):1219-1236, doi:10.1016/50967-0645(03)00019-5

Gripenberg S, Roslin T (2007) Up or down in space? Uniting the bottom-up versus top-down paradigm and spatial ecology. Oikos 116(2):181-188, doi:10.1111/j.0030-1299.2007.15266.x

Hairston NG Jr, Hairston NG Sr (1993) Cause-effect relationships in energy flow, trophic structure, and interspecific interactions. Am Nat 142:379-411, doi:10.1086/285546

Hoekman D (2010) Turning up the heat: temperature influences the relative importance of top-down and bottom-up effects. Ecology 91(10):2819-2825, doi:10.1890/10-0260.1

Hsieh CH, Kim HJ, Watson W, Emanuele DL, Sugihara G (2009) Climate-driven changes in abundance and distribution of larvae of oceanic fishes in the southern California region. Glob Chang Biol 15:2137-2152, doi:10.1111/j.13652486.2009.01875.x

Hsieh H-Y, Lo W-T, Wu L-J, Liu D-C, Su W-C (2011) Monsoon-driven succession of the larval fish assemblage in the East China Sea shelf waters off northern Taiwan. J Oceanogr 67(2):159-172, doi:10.1007/s10872-011-0015-6

Hunter MD, Price PW (1992) Playing chutes and ladders heterogeneity and the relative roles of bottom-up and top-down forces in natural communities. Ecology 73(3):724-732, doi: citeulike-article-id:3178334

Ichikawa H, Beardsley RC (2002) The current system in the Yellow and East China Seas. J Oceanogr 58(1):77-92, doi:10.1023/A:1015876701363

Iverson RL (1990) Control of marine fish production. Limnol Oceanogr 35:1593-1604

Jeppesen E, Jensen JP, Jensen C, Faafeng B, Hessen DO, Sondergaard M, Lauridsen T, Brettum P, Christoffersen K (2003) The impact of nutrient state and lake depth on top-down control in the pelagic zone of lakes: a study of 466 lakes from the temperate zone to the arctic. Ecosystems 6(4):313-325, doi:10.1007/s 10021-002-0145-1

Jeppesen E, Peder Jensen J, Søndergaard M, Lauridsen T, Junge Pedersen L, Jensen L (1997) Top-down control in freshwater lakes: the role of nutrient state, submerged macrophytes and water depth. Hydrobiologia 342343:151-164, doi: 10.1023/A:1017046130329

Lan Y-C, Lee M-A, Chen W-Y, Hsieh F-J, Pan J-Y, Liu D-C, Su W-C (2008) Seasonal relationships between the copepod community and hydrographic conditions in the southern East China Sea. ICES J Mar Sci 65(3):462-468, doi:10.1093/ icesjms/fsm173

Lefébure R, Degerman R, Andersson A, Larsson S, Eriksson LO, Båmstedt U, Byström P (2013) Impacts of elevated terrestrial nutrient loads and temperature on pelagic food-web efficiency and fish production. Glob Chang Biol 19(5):1358-1372, doi:10.1111/gcb.12134

Li Y, Chen Y, Olson D, Yu N, Chen L (2009) Evaluating ecosystem structure and functioning of the East China Sea Shelf ecosystem, China. Hydrobiologia 636(1):331-351, doi:10.1007/s10750-009-9964-9

Liao CH, Chang WJ, Lee MA, Lee KT (2006) Summer distribution and diversity of copepods in upwelling waters of the southeastern East China Sea. Zool Stud 45:378-394

Liu K-K, Chao S-Y, Lee H-J, Gong G-C, Teng Y-C (2010) Seasonal variation of primary productivity in the East China Sea: a numerical study based on coupled physical-biogeochemical model. Deep Sea Res Part II: Top Stud Oceanogr 57(19-20):1762-1782, doi:10.1016/j.dsr2.2010.04.003

Liu KK, Gong GC, Lin SW, Yang CY, Wei CL, Pai SC, Wu CK (1992) The year-round upwelling at the shelf break near the northern tip of Taiwan as evidenced by chemical hydrography. Terr Atmos Ocean Sci 3(3):243-276

Liu WH, Zhan BY (1999) The dynamic analysis on the fishery stocks in the East China Sea. J Shanghai Fish Univ 8:19-24

Llope M, Licandro P, Chan K-S, Stenseth NC (2012) Spatial variability of the plankton trophic interaction in the North Sea: a new feature after the early 1970s. Glob Chang Biol 18(1):106-117, doi:10.1111/j.1365-2486.2011.02492.x

Mallin MA, Paerl HW (1994) Planktonic trophic transfer in an estuary: seasonal, diel, and community structure effects. Ecology 75(8):2168-2184, doi:10.2307/ 1940875

Mollmann C, Muller-Karulis B, Kornilovs G, St John MA (2008) Effects of climate and overfishing on zooplankton dynamics and ecosystem structure: regime shifts, trophic cascade, and feedback loops in a simple ecosystem. ICES J Mar Sciffsm197. doi:10.1093/icesjms/fsm197

Nakagawa S, Schielzeth H (2013) A general and simple method for obtaining R2 from generalized linear mixed-effects models. Methods Ecol Evol 4(2):133-142, doi:10.1111/j.2041-210x.2012.00261.x

Okazaki Y, Nakata H (2007) Effect of the mesoscale hydrographic features on larval fish distribution across the shelf break of East China Sea. Cont Shelf Res 27:1616-1628, doi:10.1016/j.csr.2007.01.024

Omori M (1965) A $160 \mathrm{~cm}$ opening-closing plankton net. I. Description of the gear. J Oceanogr Soc Jpn 21:212-220

Pauly D, Christensen V, Dalsgaard J, Froese R, Torres F Jr (1998) Fishing down marine food webs. Science 279(5352):860-863, doi:10.1126/science.279.5352.860

Post DM (2002) The long and short of food-chain length. Trends Ecol Evol 17(6):269-277, doi:10.1016/50169-5347(02)02455-2

Richardson TL, Jackson GA (2007) Small phytoplankton and carbon export from the surface ocean. Science 315:838-840, doi:10.1126/science.1133471

Sánchez F, Olaso I (2004) Effects of fisheries on the Cantabrian Sea shelf ecosystem. Ecol Model 172(2-4):151-174, doi:10.1016/j.ecolmodel.2003.09.005

Takahashi D, Morimoto A (2013) Mean field and annual variation of surface flow in the East China Sea as revealed by combining satellite altimeter and drifter data. Prog Oceanogr 111:125-139, doi:10.1016/j.pocean.2013.01.007

Toms JD, Lesperance ML (2003) Piecewise regression: a tool for identifying ecological thresholds. Ecology 84(8):2034-2041, doi:10.1890/02-0472

Tseng L-C, Souissi S, Dahms H-U, Chen Q-C, Hwang J-S (2008) Copepod communities related to water masses in the southwest East China Sea. Helgoland Mar Res 62(2):153-165, doi:10.1007/s10152-007-0101-8

Ware DM, Thomson RE (2005) Bottom-up ecosystem trophic dynamics determine fish production in the Northeast Pacific. Science 308(5726):1280-1284, doi:10.1126/science.1109049

Wiebe PH (1988) Functional regression equations for zooplankton displacement volume, wet weight, dry weight, and carbon: a correction. Fish Bull 86:833-835

Ye L, Chang CY, García-Comas C, Gong GC, Hsieh CH (2013) Increasing zooplankton size diversity enhances the strength of top-down control on phytoplankton through diet niche partitioning. J Anim Ecol 82(5):1052-1061, doi:10.1111/1365-2656.12067

Ye L, Chang CY, Hsieh CH (2011) Bayesian model for semi-automated zooplankton classification with predictive confidence and rapid category aggregation. Mar Ecol Prog Ser 441:185-196, doi:10.3354/meps09387

\section{Submit your manuscript to a SpringerOpen ${ }^{\odot}$ journal and benefit from:}

- Convenient online submission

- Rigorous peer review

- Immediate publication on acceptance

- Open access: articles freely available online

High visibility within the field

- Retaining the copyright to your article

Submit your next manuscript at $>$ springeropen.com 